DOSSIÊ TEMÁTICO: Perspectivas para pensar as cidades: infâncias, educação, democracia e justiça

do] https://doi.org/10.22481/praxisedu.v16i40.6887

\title{
REDISTRIBUIÇÃO, RECONHECIMENTO E REPRESENTAÇÃO: UMA LEITURA DE NANCY FRASER COM O OLHAR DA INFÂNCIA ${ }^{1}$
}

\author{
REDISTRIBUTION, RECOGNITION AND REPRESENTATION: A NANCY FRASER \\ READING WITH CHILDREN'S VIEW
}

\begin{abstract}
REDISTRIBUCIÓN, RECONOCIMIENTO Y REPRESENTACIÓN: UNA FRASER NANCY LECTURA CON VISTA INFANTIL
\end{abstract}

\section{Lourdes Gaitán Muñoz}

Associação Grupo de Sociologia da Criança e do Adolescente - Espanha

\begin{abstract}
Resumo: Justiça social ou justiça distributiva é um tema central da filosofia moral, assim como é para a orientação de políticas públicas envolvidas na distribuição de recursos sociais. No campo da sociologia da infância, essa dimensão tem sido estudada principalmente quando se trata da posição da criança em relação ao bem-estar social, o tipo e o grau de sua participação nos benefícios oferecidos pelo Estado, bem como a natureza e o conteúdo das políticas da infância. No entanto, a infância está fora do debate geral sobre o significado da justiça que está ocorrendo atualmente. Como em outros aspectos, as pessoas dedicadas à produção de pensamento ou conhecimento são adultos que compartilham com seus pares um conceito de infầncia entendido como "não-ser" e de crianças como quem "já será, mas ainda não ". Mas não é necessário forçar o argumento daqueles que refletem sobre a justiça, entendendo-a como a maneira pela qual as diferentes pessoas que compõem a sociedade podem receber tratamento igual, para encontrar seu vínculo com a linguagem da sociologia da infância, quando exige o reconhecimento das habilidades das crianças ou do direito de serem portadoras de benefícios sociais para elas mesmas. Este artigo se baseará na análise das propostas de Nancy Fraser para mostrar sua aplicabilidade à posição das crianças em relação à justiça.
\end{abstract}

Palavras-chave: Justiça. Infância. Nancy Fraser.

Abstract: Social justice or distributive justice is a central theme of moral philosophy, as well as for the orientation of public policies involving the distribution of social resources. In the sociology of childhood field, this dimension has been studied mainly when it comes to the child's relation to social welfare, type and degree of his participation in the benefits provided by the State, and the nature and content of childhood policies as well. However, childhood is out of the current debate that discusses the meaning of social justice. Like other topics, the

\footnotetext{
${ }^{1}$ Texto originalmente escrito em espanhol, com tradução livre realizada por Marcia Aparecida Gobbi e revisão técnica de Sônia Larrubia e Monique Voltarelli. Resumo em inglês elaborado por Maria Cristina Stello Leite.
} 
people leading the knowledge creation are adults who share with their peers a misconception of childhood as "not-being" and children as "who will be, but not yet". But it is not necessarily adequate the argument of those who reflect on justice, understanding it as how the different people who compound society could receive equal treatment, to find their link with the language of childhood sociology, when it requires acknowledgment of children's abilities or their right to hold social benefits themselves. This article will be based on the analysis of Nancy Fraser's proposals to show its applicability to the children's position concerning justice.

Keywords: Justice. Childhood. Nancy Fraser.

Resumen: La justicia social o la justicia distributiva es un tema central de la filosofía moral, como lo es para la orientación de las políticas públicas implicadas en la distribución de los recursos sociales. En el campo de la sociología de la infancia, esta dimensión se ha estudiado principalmente cuando se trata de la posición del niño en relación con el bienestar social, el tipo y grado de su participación en las prestaciones que ofrece el Estado, así como la naturaleza y el contenido de las políticas infantiles. Sin embargo, la infancia está fuera del debate general sobre el significado de la justicia que se está produciendo actualmente. Como en otros aspectos, las personas dedicadas a la producción de pensamiento o conocimiento son adultos que comparten con sus compañeros un concepto de la infancia entendido como "no ser" y los niños como los que "ya lo serán, pero aún no". Pero no es necesario forzar el argumento de quienes reflexionan sobre la justicia, entendiéndola como la forma en que las diferentes personas que conforman la sociedad pueden recibir el mismo trato, para encontrar su vínculo con el lenguaje de la sociología de la infancia, cuando requiere el reconocimiento de las capacidades de los niños o el derecho a soportar beneficios sociales por sí mismos. Este artículo se basará en el análisis de las propuestas de Nancy Fraser para mostrar su aplicabilidad a la posición de los niños en relación con la justicia.

Palabras clave: Justicia. Infancia. Nancy Fraser

\section{Introdução}

Este artigo tem como objetivo explorar a possibilidade de introduzir o pensamento sociológico sobre as crianças no debate atual sobre justiça. Para isso, o exame do trabalho da filósofa contemporânea Nancy Fraser tem sido tomado de forma única, devido à proximidade que pode ser encontrada entre suas abordagens e algumas das questões que ocupam e dizem respeito à sociologia da infância. E isso até mesmo para seu pesar, como será explicado mais tarde.

Como em outros aspectos, aqueles que estão engajados no pensamento ou na produção de conhecimento científico são adultos, que, por sua vez, compartilham com a maioria de seus pares um conceito de infância entendido como um "não-ser" e que qualifica as crianças como quem "já será, mas ainda não são". É como se, para os teóricos, as questões ontológicas básicas, o que é uma criança? e como é possível a criança como tal? fossem respondidas com antecedência e depois descartadas, deixando viva a concepção de uma hierarquia de status entre 
adultos e crianças. Tal hierarquia é assumida e implícita na teorização do que constitui a diferença com o Outro (a criança em nosso caso). Esses pressupostos ontológicos implícitos incorporam os valores e interesses dos teóricos, ao mesmo tempo em que geram modelos do mundo social (JENKS, 1992, p.10).

Essa negligência para com as crianças no âmbito da teoria, seja por esquecimento, exclusão ou indiferença, não impede que propostas teóricas mais amplas sejam suscetíveis a uma leitura "com o olhar das crianças", encontrando assim sua conexão com os paradigmas da sociologia da infância, a fim de tirar meninas e meninos da zona de sombras em que parecem estar isolados. Este é o caso da tese inicial e seu desenvolvimento subsequente que Nancy Fraser vem articulando em torno da justiça no mundo de hoje. Ela é conhecida por abordar redistribuição e reconhecimento como duas dimensões da justiça, entre as quais um falso dilema é colocado a partir de sua perspectiva. A estes, mais tarde, adicionou uma terceira dimensão, a da representação, tudo isso se referindo à paridade participativa na vida política. Não é difícil encontrar a proximidade desses conceitos com outros conhecidos na sociologia da infância, como os da justiça distributiva (referindo-se à posição das crianças na partilha de benefícios para o bem-estar social), agência (relacionada ao reconhecimento de meninas e meninos como atores sociais hoje) e cidadania (vinculada à participação efetiva ou potencial na vida pública e comunitária).

Para demonstrar tanta proximidade, este artigo está estruturado em algumas etapas. Em primeiro lugar, será feita uma breve descrição das principais questões propostas e desenvolvidas pela filósofa feminista. Em segundo lugar, serão trazidos à tona tanto os argumentos originais quanto os mais recentes sobre justiça para crianças dentro da sociologia da infância, levando em consideração três dimensões, que são a distribuição de recursos sociais, agência ou ator social e a participação como condição de cidadania. Finalmente, antes de apresentar algumas conclusões, será feita uma proposta de aplicação dos conceitos básicos contidos nas orientações de Fraser que foram implicados à explicação teórica do lugar da infância e da adolescência hoje, no campo designado da justiça.

\section{Redistribuição, reconhecimento e paridade participativa}

O ponto de partida de Fraser para a elaboração de sua proposta teórica foi a observação de que, no final do século XX, as lutas por justiça baseadas na existência de desigualdades de classe, pareciam ter dado lugar à luta pelo "reconhecimento da diferença" por grupos mobilizados sob as bandeiras relacionadas à nacionalidade, etnia, "raça", sexualidade ou 
gênero. Segundo a autora, esses dois tipos de demandas por justiça, muitas vezes, aparecem dissociadas, tanto na prática, quanto intelectualmente, havendo, eventualmente uma polarização e dissociação entre ambos. O propósito de Fraser é provar que são falsas antíteses, e que a justiça exige redistribuição e reconhecimento.

Seu artigo mais conhecido, "De la redistribución al reconocimiento? Dilemas de la justicia en la era postsocialista" foi publicado no livro Justice Interruptus. Critical Reflections on the Postsocialist Condition (FRASER, 1997). Antes desta publicação, seu conteúdo foi tema de uma palestra ministrada na Universidade de Michigan em março de 1995 (FRASER, 2000, 2016), enquanto, em outra conferência, realizada em Santiago de Compostela (Espanha) em junho de 1996 (FRASER, 1996), a autora já expôs suas ideias, não apenas sobre a redistribuição e o reconhecimento como desafios para a justiça social, mas também avançou para a consideração de "paridade participativa", dimensão que dá origem a um terceiro termo na construção analítica de Fraser, qual seja, o de representação.

No artigo primeiramente citado, Fraser aborda sua argumentação em quatro partes. Na primeira, conceitua a redistribuição e o reconhecimento como dois paradigmas analíticos diferentes da justiça e formula o dilema "redistribuição-reconhecimento". Na segunda, distingue três modos ideais de comunidade social para identificar aquelas que são vulneráveis a este dilema. $\mathrm{Na}$ terceira estabelece a distinção entre as soluções "afirmativas" e "transformadoras" da injustiça e examina suas respectivas lógicas comunitárias. Por fim, propõe uma estratégia política que integre os requisitos de reconhecimento com os requisitos de redistribuição com mínima interferência mútua.

Os conceitos de redistribuição e reconhecimento são apresentados como formas de solução para dois tipos de injustiça: injustiça de origem econômica (que está enraizada na estrutura econômico-política da sociedade) e injustiça de origem cultural ou simbólica (enraizada em modelos sociais de representação, interpretação e comunicação). Ambos os tipos de injustiça são difundidos nas sociedades contemporâneas, prejudicando alguns grupos de pessoas versus outros, por isso ambos exigem uma solução (FRASER, 2016). O dilema consiste em que dois tipos de injustiça precisam de soluções analiticamente diferentes e que pressionam para direções opostas.

Continuando seu raciocínio analítico, Fraser sugere que representemos um espectro conceitual composto por modelos ideais de comunidades sociais. Em um lado, seriam as formas comunitárias que se conformam com o modelo de justiça de redistribuição, na outra ponta aquelas que se encaixam no modelo de reconhecimento. Na primeira dessas comunidades, a 
raiz da injustiça, seu núcleo, será a má distribuição socioeconômica. No segundo, a raiz da injustiça e seu núcleo serão o reconhecimento inadequado. Formas complexas estão localizadas entre eles, pois correspondem simultaneamente com ambos os modelos de justiça e formas de injustiça. Neste caso, são comunidades "bivalentes", que diferem tanto em virtude da estrutura econômico-política quanto da estrutura de valorização cultural da sociedade, exemplos delas seriam de gênero e raça.

Em suas conclusões, Fraser acredita que a tarefa é criar maneiras de refinar o dilema reconhecimento-redistribuição quando ele estiver situado no campo de lutas múltiplas e entrelaçadas contra injustiças múltiplas e entrelaçadas. Para a autora, a combinação entre socialismo e desconstrução cultural, como alternativas transformadoras, é superior a outras alternativas para superar o dilema aqui exposto.

De outro ângulo, Fraser (2006) argumenta que os termos de redistribuição e reconhecimento têm uma referência filosófica e política. Em um sentido filosófico, a redistribuição vem da tradição liberal do final do século XX (RAWLS; DWORKIN) que tentam sintetizar a insistência liberal tradicional na liberdade individual, com o igualitarismo da democracia, de modo que ambos (liberdade e igualdade) servem de base para a ideia de redistribuição inspiradora do estado de bem-estar social. Por outro lado, segue a autora, o termo reconhecimento vem da filosofia hegeliana, tomada por autores como Taylor e Honneth, designando uma relação recíproca ideal entre sujeitos, constitutiva da subjetividade: torna-se um sujeito individual apenas em virtude de reconhecer ao outro sujeito e ser reconhecido por ele.

Dessa forma, os conceitos de "redistribuição" e "reconhecimento" são difíceis de conciliar. Fraser então se concentra na dimensão política desses termos, que ela entende como uma expressão das reivindicações atualmente em discussão nas esferas públicas, relacionadas à forma popular de compreender as causas e soluções da injustiça. Segundo ela, paradigmas populares de redistribuição e reconhecimento diferem em quatro aspectos-chave (2006, p. 2225):

$1^{\circ}$ Assumem diferentes concepções de injustiça (socioeconômica versus cultural).

$2^{\circ}$ Propõem diferentes tipos de soluções (reestruturação econômica/mudança cultural ou simbólica).

$3^{\circ}$ Assumem diferentes concepções das coletividades que sofrem injustiça (a classe trabalhadora explorada/grupos com menor respeito, estima e prestígio). $4^{\circ}$ Sustentam ideias distintas dos diferenciais de injustiça do grupo (no primeiro caso, seria abolir as classes, no segundo, de manter diferenças). 
Um e outro tipo de reivindicações constituem dois extremos, entre os quais há muitas posições intermediárias, as quais Fraser chama de "bivalentes", pois estão arraigadas na estrutura e na ordem de status da sociedade, implicando injustiças que podem ser atribuídas a ambas as realidades. Grupos bidimensionais subordinados sofrem tanto de má distribuição quanto de equívocos, portanto nenhuma dessas injustiças é um efeito direto da outra, mas ambos são primários e co-originais. Portanto, nem uma política de redistribuição nem uma de reconhecimento por si só é suficiente, mas ambas são necessárias para satisfazer a aspiração da justiça. Segundo Fraser, gênero e "raça" são comunidades bivalentes paradigmáticas, mas os argumentos para classificá-los dessa forma são válidos para todas as comunidades bivalentes.

Os argumentos iniciais de Fraser, e sua afirmação de que "não pode haver reconhecimento sem redistribuição ou redistribuição sem reconhecimento", foram desenvolvidos na forma de debate político-filosófico com Axel Honneth, publicado em alemão em 2003 (FRASER; HONNETH, 2006). Mas será um pouco mais tarde quando a filósofa começar a desenvolver a questão dos obstáculos políticos à paridade participativa, o que a leva a levantar uma terceira dimensão da justiça, ou seja, representação política.

O conceito de paridade de participação aparece no texto citado, como o marco regulatório da referência para colocar a redistribuição e o reconhecimento. E assim para Fraser, de acordo com esta norma: "a justiça exige acordos sociais que permitam a todos os membros (adultos) da sociedade interagir em pé de igualdade" (2006, p.42).

Para isso, duas condições devem ser cumpridas: (1) que a distribuição dos recursos materiais garanta independência e "voz" de todos (condição objetiva) e (2) que padrões institucionalizados de valor cultural expressem o mesmo respeito a todos os participantes e garantam igualdade de oportunidades para alcançar a estima social (status intersubjetivo). Desta forma, ela afirma:

[...] a paridade participativa é uma norma universalista de duas maneiras. Primeiro, abrange todos (adultos) envolvidos na interação. Em segundo lugar, pressupõe o valor moral igual dos seres humanos. (2006, p. 49).

Em Escalas da Justiça, (FRASER, 2008) ela retoma a questão afirmando que "o significado mais geral da justiça é a paridade de participação" e, assim, superar a injustiça significa "desmantelar os obstáculos institucionalizados que impedem alguns de participar em par com outros, como parceiros plenos na interação social" (p. 39). Assim, juntamente com os obstáculos à paridade participativa decorrentes da falta de reconhecimento (equívoco) e de uma distribuição inadequada (má distribuição), seriam aqueles que surgem da constituição política 
da sociedade e se referem à natureza da jurisdição do Estado e às suas regras de decisão. A política proporciona o cenário em que ocorrem as lutas pela distribuição e reconhecimento, mas ao mesmo tempo especifica o escopo dessas duas dimensões, na definição de quem está incluído e quem é excluído do círculo daqueles que têm direito à distribuição justa e ao reconhecimento mútuo.

Para Fraser, a "gramática da justiça" agora inclui tanto o que é devido como matéria de justiça aos membros de uma comunidade, quem deve contar como membro, quem é a comunidade relevante, e porquê. Esta última questão, diz ela, inaugura uma mudança de paradigma: o quadro westfálnico-keynesiano (que se refere à adesão a um Estado-nação) deve se tornar uma referência de justiça democrática póswestfaliana ${ }^{2}$ global.

\section{Redistribuição, reconhecimento e representação na sociologia da infância}

Esta seção desenvolverá três abordagens para a questão da justiça feita a partir da sociologia da infância. Por um lado, justiça distributiva para as crianças, por outro, seu reconhecimento como atores sociais e, por fim, sua participação na vida social, relacionada à questão da cidadania. São três dimensões que ocuparam e mantêm um grande espaço na prática teórica e de pesquisa desta subdisciplina sociológica (VOLTARELLI ET AL., 2018).

\section{Justiça distributiva}

A justiça distributiva foi um dos temas escolhidos para ser desenvolvido por cada país no projeto Childhood as a Social Phenomenon. Nunca antes a sociologia se ocupou em estudar a questão da justa atribuição de recursos sociais dedicados às crianças e sua distribuição entre diferentes gerações. A razão fundamental para introduzir esse conceito foi a consideração de que as crianças estão fora do que se entende em nossa cultura como uma distribuição justa de recursos, ou seja, aquela que ocorre como resultado de uma troca justa. Assim, o benefício que uma pessoa obtém é proporcional ao seu investimento, seus méritos, seus próprios direitos ou as suas necessidades. As crianças estão fora dessas regras, exceto aquela baseada nas necessidades: não são investidores, não têm méritos, possuem alguns direitos, mas isso é

\footnotetext{
${ }^{2}$ Nota da tradutora: este é um enfoque da justiça como paridade participativa, que permite uma abordagem da justiça democrática e reflexiva.
} 
excepcional, porque não têm o status de titulares. Sua única opção, então, é receber uma distribuição justa com base nas necessidades (QVORTRUP, 1990a).

A função distributiva é característica dos estados de bem-estar social, função que se realiza através da disposição de uma política fiscal que prejudica a renda, que é redistribuída na forma de transferências sociais. O objetivo é garantir a cobertura das necessidades básicas, com a maior eficiência econômica, abordando as desigualdades como forma de alcançar maior coesão social. A questão central levantada naquele projeto internacional foi analisar se os critérios de distribuição adotados nos diferentes países (todos pertencentes ao mundo ocidental) permitiram que as crianças fossem devidamente incluídas na partilha dos benefícios comuns da sociedade. Em outras palavras, saber se o que a infância recebe responde aos princípios da justiça para os meninos e as meninas. No balanço dos resultados do projeto destacam algumas questões que serão expostas a seguir.

Em primeiro lugar, sublinha-se que, de entrada, os autores tiveram que lidar com questões filosóficas sobre o que significa o conceito de justiça distributiva e o que ela implica. Filosoficamente, a noção de justiça distributiva baseia-se no pressuposto de que há uma forma correta, eticamente justificável, moral ou justa de alocar recursos sociais entre membros de uma sociedade. Nesse sentido, há, sem dúvida, unanimidade na prática de que as crianças não devem sofrer qualquer discriminação em relação à população adulta (QVORTRUP, 1990b, p. 29). Uma segunda questão filosófica consiste em elucidar se a idade deve dar origem a uma distribuição discriminatória, para que as crianças tenham direito a diferentes níveis (maiores ou menores) de recursos sociais do que os membros adultos da população, isto é, se a idade pudesse ser um critério de distribuição, sem que isso conflite com outros critérios de valor social. Até agora, nas sociedades capitalistas, os critérios mais comuns são: o intercambio justo (no mercado), mérito e necessidade. Segundo eles, as crianças só teriam que reivindicar recursos com base no critério de necessidade, como já mencionado, uma vez que não têm nada a contribuir para o mercado e não possuem méritos reconhecidos. Somado a isso, deve-se dizer que os recursos que recebem geralmente chegam a eles através dos benefícios que são dados aos seus pais.

Um segundo aspecto examinado neste projeto foi a distribuição geracional dos recursos sociais. Para isso, os pesquisadores nacionais procuraram selecionar uma série de elementos de seus respectivos orçamentos públicos, para ver se alguma ou algumas das gerações coexistentes eram melhores ou pior tratadas neles. Os resultados foram inconclusivos, exceto na área de pobreza, onde a proporção de crianças nesta situação acabou sendo substancialmente 
maior do que a de toda a população. Também descobriram que a distribuição do espaço habitacional difere consideravelmente entre crianças e outros grupos (1993, p. 30-31).

A questão da justiça distributiva vista de uma perspectiva intergeracional foi retomada anos depois por Olk e Wintersberger (2007) e por Olk (2011). Thomas Olk ressalta que, no que diz respeito às relações geracionais entre meninos e meninas com outras gerações, dois níveis de análise podem ser identificados: um microsociológico e outro macrosociológico. A partir do micro, as crianças são consideradas atores sociais que interagem com outras pessoas e grupos. Do ponto de vista macrosociológico, a infância pode ser descrita como um coletivo que pode ser comparado a outras comunidades, como a idade adulta ou a velhice (2011, p. 189).

$\mathrm{Na}$ ocasião, diferencia quatro formas de aplicação do conceito de geração relevante na filosofia e na teoria social, que correspondem a diferentes e parcialmente conflitantes conceitos de justiça re-distributiva (op.cit., p, 190-191):

Ver a crianças, adultos e idosos como unidades pessoais coexistindo em um momento específico no tempo. A Justiça refere-se, neste caso, aos critérios de distribuição entre as três gerações e seu desfecho.

Considerar a sucessão de diferentes gerações ao longo do tempo em que indivíduos pertencentes ao mesmo grupo geracional (crianças, por exemplo), mas viver em momentos diferentes seriam afetados por fenômenos diferentes, o que produziria diferenças qualitativas entre eles do ponto de vista da justiça.

Estabelecer uma comparação dos ciclos de vida completos: equilíbrio de coorte, por exemplo, coortes de pessoas idosas que vivem agora, com as quais viverão no futuro. Em termos de justiça, o tratamento justo das gerações sucessivas significaria que as gerações futuras terão pelo menos um nível mínimo de pensão equivalente ao atual.

Colocando o foco nas gerações futuras: como as gerações atuais estão limitando as oportunidades de vida de gerações sucessivas, por exemplo, por causa da destruição ecológica.

De acordo com Olk e Wintersberger (2007, p. 86) nos últimos anos, na Europa houve uma mudança na ideia predominante de justiça do "distributivismo" para o "produtivismo" (cf. ESPING-ANDERSEN ET AL., 2002), que seria enquadrado na busca de um equilíbrio semelhante ao identificado no terceiro ponto acima. Uma das consequências dessa mudança, dizem os autores, foi a percepção das crianças como "trabalhadores produtivos do futuro". De acordo com o argumento "investimento em crianças", apoiado por Esping-Andersen e presente em inúmeros documentos da União Europeia e algumas organizações infantis influentes, tal coisa aumentaria tanto o bem-estar da população em geral quanto a competitividade da 
economia nacional de um determinado país. Olk e Wintersberger consideram que, do ponto de vista do interesse de meninas e meninos, este argumento é problemático, pois torna seu bemestar atual dependente de possíveis retornos futuros, negando assim seu direito de desfrutar de uma boa infância e de satisfazer seus desejos e necessidades aqui e agora (op.cit., p. 86). Uma forma de combater esse argumento, segundo os autores citados, é defender a utilidade atual das atividades das crianças, por exemplo, na área da educação, essencial para a manutenção e o progresso dos processos produtivos. Assim, a provisão social deixaria de ser entendida como benefícios imerecidos, mas como compensação por atividades socialmente valorizadas. Ao mesmo tempo, esta seria uma estratégia convincente para projetar justiça social para as crianças, não como uma expressão de equidade intergeracional, mas, sobretudo, como justiça para crianças como crianças (OLK, 2011).

\section{Atores sociais}

A ideia de agência (agency) tem sido um dos mais importantes desenvolvimentos teóricos da história recente dos estudos da infância. James e Prout (1997), em um dos textos mais proeminentes da nova sociologia da infância, fornecem uma definição do que significa falar sobre crianças como atores sociais:

As crianças são e devem ser vistas como ativas na construção e determinação de suas próprias vidas sociais, a vida daqueles ao seu redor e as sociedades em que vivem. As crianças não são apenas as pessoas tributáveis das estruturas e processos sociais. (op. cit., p.8)

A pesquisa social baseada nesse paradigma tem demonstrado amplamente o papel das meninas e meninos como atores efetivos na vida social, mas ao mesmo tempo a reflexão teórica sobre o significado do conceito tem sido mantida, a partir do fato de que não basta afirmar, axiomaticamente, que elas e elas são atores, mas que também é necessário explorar as diferentes dimensões que essa afirmação implica ao se referir às crianças e, além disso, inserir essa afirmação no discurso corrente dentro das ciências sociais.

A visão dominante nas ciências sociais antes dos anos 70 do século passado era que atuar na sociedade exige um grau de estabilidade e competência que é típico dos adultos, mas ainda não foi alcançado pelas crianças. Nessa perspectiva, se as crianças são estudadas é porque são consideradas representantes de uma categoria cuja significância repousa, principalmente no que elas revelam sobre a vida adulta (JAMES, 2011). Mas a partir desses anos houve uma 
mudança de paradigma que significava começar a ver as crianças como atores sociais que merecem ser estudadas "por si mesmas" e não como apêndices para outras instituições, como a família ou o sistema educacional, ou como partes de outros fenômenos, como o desvio social.

Essa mudança de paradigma para as crianças coincide com mudanças na posição das crianças na sociedade e com uma crítica emergente das perspectivas tradicionais no estudo das crianças. Na perspectiva sociológica (antes dominada pela versão funcionalista da socialização) foi preponderante o reconhecimento da divisão entre teorias que buscam explicar a estrutura da vida social e aquelas que exploram as ações e significados dos indivíduos. Anthony Giddens (2000) tentou integrar ambos os conceitos através de sua teoria da estruturação. Trata-se de uma teoria extraordinariamente eclética que é essencialmente resumida por seu próprio autor quando afirma que o domínio básico do estudo das ciências sociais não é nem a experiência do ator individual, nem a existência de qualquer forma de totalidade social, mas práticas sociais ordenadas através do tempo e do espaço. Para o sociólogo inglês, a ação e estrutura estão indissociáveis ligados em toda atividade ou prática humana. A forma mais satisfatória de estabelecer uma ponte entre a abordagem "estrutural" e a de "ação" é admitir que estamos todos ativamente envolvidos na construção e reconstrução da estrutura social no decorrer de nossas atividades diárias.

Se aceitarmos a explicação de Giddens sobre a interação entre estrutura e ação, então as crianças devem ser consideradas, como adultos, participantes ativos na sociedade, como interagem entre si e com os outros, ao mesmo tempo em que são influenciadas pela estrutura e a influenciam (GAITAN, 2014).

A corrente do que inicialmente foi chamado de nova sociologia da infância, assumiu como um de seus fundamentos básicos a consideração das crianças como atores sociais, ou seja, elas e eles "participam das relações familiares a partir do momento zero; expressar seus desejos, demonstrar fortes apegos, ciúme e prazer, buscar justiça (MAYALL, 2000, p. 21). Mayall ressalta, no entanto, que, além disso, é necessário mostrar que as crianças também são atores na esfera social. Nesse sentido, fixa-se na diferença entre dois termos, o de "ator" e o de "agente", que embora tenham a mesma raiz etimológica, em seu uso podem ser divergentes. Segundo ela, um "ator" faz algo, talvez algo que surge de um desejo subjetivo, enquanto o termo "agente" sugere uma dimensão maior, ou seja, uma negociação com os outros, que produz diferenças na relação, ou em decisões que possam resultar dessa interação. É por isso que a "agência" das crianças deve ser entendida dentro do status minoritário da infância. A infância é entendida como um período de desenvolvimento sob a proteção dos adultos, o que implica, 
segundo Mayall, relações de poder desiguais. Por essa razão, para a maioria dos adultos, diz-se que as crianças são agentes que despertam resistência e dúvidas sobre que tipo de atores eles são e o que podem agir. Segundo Mayall, isso se deve à influência da psicologia evolutiva, que nos ensinou a achar difícil aceitar a ideia da criança como ator moral.

De fato, a falta de competência moral é um argumento recorrente para negar às crianças sua autonomia e direitos. Nessa visão, as crianças são rotuladas como imaturas, não apenas físicas, mas também emocional e intelectualmente; além disso, são considerados sem a experiência necessária para saber o que é bom e o que é ruim (VERHELLEN, 1993, p. 59). Para Achard e Mcleod (2002), as crianças não foram objeto de discussões filosóficas extensivas até tempos mais recentes, e isso aconteceu no decorrer das discussões sobre seus direitos. No entanto, há duas ideias sobre o que venha a ser crianças na história da filosofia moral e política. A primeira ideia é que as crianças são simplesmente propriedade de seus pais. A segunda ideia é que as crianças são proto-adultos ou seres incompletos, o que tem algumas implicações negativas importantes. Assim, as crianças são vistas pelo que não são, mais do que pelo que são em si mesmas. Além disso, o passo em direção à maturidade é essencialmente considerado o da inadequação (vulnerabilidade, fraqueza, dependência, ignorância, passividade) às conquistas da idade: segurança, força, independência, conhecimento e agência.

Do nosso ponto de vista (GAITÁN, 2014a) o problema não está tanto na capacidade de ação das crianças, mas precisamente na falta de reconhecimento como atores e também se deve "à falta de estruturas democráticas e ao domínio de um tipo de conhecimento sobre crianças que não reconhece crianças como pessoas completas e competentes, quando crianças" (PAVEZ; SEPULVEDA, 2019, p. 207).

\section{Participação e cidadania de crianças e adolescentes}

A falta de reconhecimento também está na base das dificuldades encontradas na defesa e demonstração da cidadania das crianças. A partir de uma cidadania entendida como um conjunto de direitos que são adquiridos na idade adulta (equivalente ao tipo que Fraser considera típico do estado westfiano-keynesiano) formas de espera e "aprendizagem" da cidadania são reservadas às crianças. Das diversas alternativas que se defendem nos estudos da infância e dos direitos de transbordamento desta configuração (GAITÁN; LIEBEL, 2011) destaca-se a da Moosa-Mitha (2005), que defende um modelo de cidadania focado na diferença. Esta autora levanta a possibilidade de reconhecer a cidadania na infância sem ter que mensurála com padrões pré-estabelecidos por e para adultos. Assim, não define a particularidade das 
crianças pela falta ou inadequação de certas competências, mas pelo fato de não terem autoridade ou "presença" suficientes para que a sociedade as leve a sério com seus pontos de vista e nessa sua condição. A cidadania seria, portanto, a implementação do direito das crianças de fazerem parte da sociedade como membros "diferentemente iguais" dela.

O tema da participação em crianças faz parte do discurso mais amplo sobre a participação como status de cidadania, que ocorre nas sociedades ocidentais, a partir da década de 1960. Dessa forma, pode ser visto como reflexo de um movimento generalizado em direção ao reconhecimento da participação como elemento central no conceito de democracia, que inclui cada vez mais camadas da população. Assim, pode-se dizer que a participação é uma questão que está ligada ao processo de democratização pelo qual vários grupos populacionais exigem maior representatividade e também são ouvidos em processos decisórios sobre as questões que os afetam (FERNÁNDEZ, 2009). No entanto, foi o discurso sobre direitos humanos na infância, nascido da aprovação da Convenção das Nações Unidas sobre os Direitos da Criança, em 1989 (doravante o CDN), que deu impulso a essa questão. Para fins pedagógicos (GAITÁN, 2018) o conteúdo da Convenção foi resumido em três "Ps": proteção, provisão e participação. Sob este último "p" há vários projetos em desenvolvimento em todo o mundo, especialmente a nível local, mas também com iniciativas representativas em nível nacional ou supranacional. Apesar dos esforços realizados, essas iniciativas não provocaram uma mudança real nas condições de participação das crianças (IAWGCP, 2008) e, na maioria dos casos, as experiências realizadas dificilmente excedem o nível do que Robert Hart (1992) chama de "participação simbólica". Isso pode ser devido a diferentes circunstâncias, mas concordamos com Wyness (2018) quando afirma que tanto profissionais quanto tomadores de decisões políticas, sejam locais ou globalmente, se estabeleceram de forma estreita e institucionalizada de compreender a participação das crianças, consistindo em um conjunto de ideias e práticas normativas, modeladas pela concepção adulta do que a participação deve significar em seu caso. Wyness chama essa forma de compreender a participação na infância como "Narrativa Dominante" (op.cit., p. 54-57).

Diante dessa narrativa dominante, as crianças que trabalham para contribuir com os próprios meios de subsistência ou para as próprias famílias, ou aquelas que às vezes desempenham papéis dominantes, não são vistas como participantes legítimas. Manfred Liebel chamou essa forma de participação das crianças de "cidadania de baixo" (LIEBEL, 2008; GAITAN; LIEBEL, 2011). A cidadania de baixo é caracterizada por uma situação de falta de poder e direitos e aparece como parte da prática do cotidiano. No caso das meninas e dos 
meninos, a cidadania de baixo significa que elas e eles "se apropriam do direito" como se já fossem cidadãos plenos, bem cientes de que estão sendo privados de certas vantagens. São maneiras pelas quais as crianças resistem ao poder dos adultos, e, inclusive os desafiam, ganhando assim a rejeição ou qualificação de serem maus cidadãos. Agora, diz Liebel, a cidadania de baixo não é uma questão individual, mas só se tornará uma realidade se as crianças desenvolverem uma consciência de seus interesses comuns. Assim como acontece com os adultos, também é necessário entre as crianças que uma associação seja formado primeiro para que, a partir daí, aqueles que compartilharam experiências comecem a se unir para alcançar uma ação comum.

Os movimentos sociais das crianças nos países do Sul global (ver LIEBEL, 2006) são um exemplo instrutivo de cidadania a partir de baixo. À primeira vista, as crianças que compõem esses movimentos carecem de condições favoráveis ou autoestima suficientes para se fazerem ouvir e captarem a atenção do público, uma vez que vivem em condições de múltiplas desvantagens. Eles não são levados a sério quando crianças; são pobres e, portanto, suas oportunidades de educação e formação são reduzidas; muitas vezes são vítimas de discriminação social e suas chances de viver experiências positivas que sustentam sua autoestima são escassas. No caso de crianças pertencentes a minorias étnicas, tudo isso se soma a ser objeto de preconceito racial e marginalização. E muitas vezes às meninas é negado o direito de participar de atividades sociais antigas fora de casa.

Assim, nos movimentos infantis do Sul, o impulso decisivo para se unir nasce da experiência comum de buscar a vida, apesar de todas as desvantagens e discriminações que sofrem. Deste modo, a necessidade de "fazer" algo para não morrer muitas vezes motiva essas crianças a formar grupos espontaneamente, cuja "autoajuda" é muitas vezes subestimada e até criminalizada como uma forma precoce ou disfarçada de delinquência. Junto com esses grupos, formados espontaneamente, que muitas vezes são vistos na situação paradoxal de ter que violar leis para usufruir de seus direitos, há movimentos infantis mais organizados, que exibem uma consciência jurídica muito pronunciada, lutando francamente, explicitamente e diretamente reivindicando seus direitos e, em alguns casos, até mesmo formulando-os eles mesmos.

Nem nas instituições próprias da democracia formal, meninos, meninas e adolescentes encontram espaço para defender seus direitos ou fazer suas reivindicações. Estamos falando da restrição imposta a pessoas menores de 18 anos em termos de direito de participar do governo de um país, direta ou por meio de representantes, reconhecidos na Declaração Universal dos Direitos Humanos. O debate sobre o voto dos menores é um debate antigo, uma vez que já no 
século XX, em alguns países, foi proposto estender o direito ao voto a todos os cidadãos desde o nascimento. Em seguida, seja em suas versões mais radicais, seja nas versões reformistas, que buscam uma extensão "gradual" dos direitos concedidos às crianças, não deixou de estar presente no debate, embora com resultados modestos, uma vez que apenas alguns países reduziram a idade de votação para 16, como tem sido feito em alguns distritos regionais ou locais. De qualquer forma, endossamos o comentário de Wintersberger (2009), ou seja, que a redução da idade para votar não deve ser interpretada como um presente generoso para jovens entre 16 e 18 anos, mas como primeira resposta da sociedade adulta a um problema de democracia, atual e perturbadora, causado pela privação de um importante grupo populacional, assim como a de crianças e adolescentes, de toda expressão política, o que implica o consequente desequilíbrio da distribuição geracional do poder político.

Para concluir esta seção, deve-se fazer referência à cidadania das crianças dentro do sistema educacional. A educação introduz as crianças na sociedade, determinando como, e quando sejam adultos e possam ser capazes de encontrar seu lugar dentro dela (GAITAN, 2014b). No entanto, os sistemas educacionais enfrentam um paradoxo: por um lado, têm a missão de formar os alunos nas virtudes da cidadania, mas ao mesmo tempo oferecem pouca chance de praticá-los, devido à desconfiança institucionalizada que estrutura as interações educacionais. Crianças e adolescentes não são agentes na educação e têm oportunidades limitadas de fazer escolhas de acordo com seu julgamento pessoal. Eles e elas parecem aceitar esse status quo, ou expressar seu mal-estar fora desses sistemas, o que só evidencia, mais uma vez, a distância entre as reivindicações retóricas que não alteram substancialmente as estruturas de poder que regem na organização dos sistemas de educação e a posição das crianças dentro deles.

\section{Pensando na infância e na justiça social desde o discurso de Nancy Fraser}

Deixando de lado essa exclusão implícita de crianças que pode ser lida nas duas citações reproduzidas anteriormente, não é possível conceber que quando Fraser se refere à justiça para todos, esse todos se refere a todos os seres humanos, exceto quando são, circunstancialmente, incluídos nas categorias da infância ou adolescência. Esta seção será, portanto, dedicada a explorar a possível aplicação dos conceitos básicos expostos e desenvolvidos por esta autora a esse grupo humano cuja característica comum e mais óbvia é que todos os seus componentes 
estão abaixo de certa idade (18 anos) que é um limite convencionalmente construído, mas que implica um conjunto de limitações em ser e agir individual ou coletivamente.

Essas limitações têm uma base biológica na longa duração do período em que os seres humanos precisam se defender com autonomia, em relação ao tempo necessário por outras espécies animais. Mas essa dependência biológica é ao mesmo tempo social, estendendo-se consideravelmente além do que a própria biologia aponta e, assim, dando origem a uma concepção de seres humanos, quando estão no estágio inicial de sua existência, como seres incompletos, sem capacidade e julgamento para governar suas próprias vidas. Talvez seja a relação com o biológico que faz a infância parecer um fato natural e não como um fenômeno socialmente construído. Elaborado de fato em oposição à imagem e atributos que se aplicam ao adulto, como uma representação de um modelo acabado de ser humano que se pretende aspirar. Trata-se de uma visão adulta da ordem social, que envolve tanto uma hegemonia do pensamento, como uma relação social assimétrica entre adultos e aqueles que compõem outras faixas etárias, como a composta por crianças e adolescentes, e também aquela que inclui os idosos. A partir dessa visão "naturalizada" da infância, os adultos que dedicam sua inteligência ao pensamento científico não são isentos, como demonstrado por esse "deslize" cometido por Fraser nas citações que estamos comentando.

A análise da posição das mulheres como um grupo subordinado à hegemonia do grupo culturalmente dominante, no âmbito das relações de poder assimétricas entre mulheres e homens, é um eixo central no pensamento de Fraser sobre justiça, e pode ser resumida em um termo (androcentrismo) semelhante ao que acabamos de recorrer às relações entre gerações:

Assim, uma característica da injustiça de gênero é o androcentrismo: ou seja, o padrão institucionalizado de valor cultural que privilegia os traços associados à masculinidade, ao mesmo tempo em que desvaloriza o que é percebido e interpretado como "feminino" — paradigmaticamente mulheres, mas não apenas elas. (FRASER, 2012, p. 272-273).

Nesta ocasião, as últimas palavras deste parágrafo nos levam a pensar em meninas e meninos. De fato, a sociologia das crianças encontrou, desde sua criação, paralelos entre as posições de mulheres e crianças, e também falou sobre os benefícios que poderiam trazer para tomar um exemplo do caminho trilhado pelos estudos femininos e movimentos feministas em termos de emancipação (pelo menos conceitualmente) das crianças. Por exemplo, Ann Oakley (1993) analisou a posição material e cultural de crianças e mulheres e como isso molda a forma das relações pessoais e sociais mútuas. Ambas (mulheres e crianças) fazem parte de dois grupos minoritários que, como tal, são constituídos dentro de uma cultura dominada pelo poder 
masculino (patriarcado), e se encontram em desvantagem como cidadãos. Por outro lado, as características compartilhadas entre mulheres e crianças, ou seja, status de grupo minoritário, relativa falta de direitos e construção moral como não adultos, refletem-se na linguagem utilizada para descrever sua posição social. É a linguagem do "melhor interesse", onde os julgamentos sobre seu bem-estar não se baseiam em perguntar-lhes o que eles querem ou o que eles precisam, mas sobre o que é considerado bom para eles, de acordo com Oakley.

No entanto, apesar de sua proximidade, a relação entre a infância e as teorias feministas nem sempre foi amigável. Como tem sido estudado até agora na sociologia da infância, gênero e geração são duas variáveis que não se cruzam, apesar das semelhanças entre os dois conceitos e do benefício indubitável que sua consideração conjunta poderia proporcionar ao estudo da vida das crianças em sociedade. Por outro lado, Mayall (2003) considera que as análises feministas são incompletas quando omitem crianças como agentes sociais e crianças como componente estrutural da ordem social. Buscando uma explicação para o esquecimento de iniciativas teóricas sobre a infância, a autora sugere que as feministas enfrentem suas alternativas dentro do pensamento social atual, portanto, o conhecimento feminista e o pensamento tradicional permanecem profundamente centrados em adultos. Para Rosen e Twamley (2018) não é apenas uma questão de um e outro ser ignorado, mas que as conexões entre mulheres e crianças não são apenas de diferença ou afinidade, mas estão profundamente ligadas a questões políticas de poder e injustiça. Por essa razão, argumentam que a compreensão das relações entre mulheres e crianças é central para qualquer projeto que procure desafiar as injustiças enfrentadas por cada grupo. De acordo com esta sugestão, é possível prosseguir com uma leitura de Fraser pensando sobre justiça para meninos e meninas aqui e agora, por ser o que são, e não pelo que serão ou chegarão a ser.

Ao contrário das mulheres, ou de outros grupos minoritários que, segundo Fraser, realizaram suas lutas ou apresentaram suas reivindicações ao longo do século passado e o que acontece com o presente, as crianças não lutam pela redistribuição, nem pelo reconhecimento e, quando o fazem, sua voz é silenciosa ou silenciada. Na verdade, até agora, foram as pessoas adultas que falaram por eles e por elas, às vezes com paternalismo ou superproteção, mas outros se esforçam para trazer à tona suas deficiências entendidas como situações de injustiça. A Convenção das Nações Unidas sobre os Direitos da Criança, tanto em sua gestação quanto em sua aplicação ou em sua crítica, forneceu o quadro para ações existentes (expressas no direito de desfrutar de um padrão de vida adequado para seu desenvolvimento físico, mental, espiritual, moral e social) e reconhecimento (como sujeitos do direito e dos atores sociais), e isso porque 
o grupo infantil pode ser considerado uma dessas comunidades bivalentes que requerem uma coisa e outra, explica Fraser:

Como comunidades, elas diferem em virtude tanto da estrutura econômicopolítica quanto da estrutura de valorização cultural da sociedade. Portanto, quando são marginalizados, podem sofrer injustiças que se referem simultaneamente à economia política e à cultura. Em suma, as comunidades bivalentes podem ser vítimas tanto da distribuição socioeconômica desfavorecida quanto do reconhecimento cultural inadequado, de modo que nenhuma dessas injustiças é uma consequência direta da outra, mas ambas são fundamentais e equivalentes em termos de suas causas. Neste caso, nem soluções redistributivas isoladas nem soluções de reconhecimento separadas serão suficientes: as comunidades bivalentes precisam de ambas. (2016, p. 40)

Seguindo Fraser, a representação refere-se a uma terceira forma de alcançar a justiça, através da superação de barreiras políticas à "paridade de participação". Embora esse conceito já estivesse presente em seus primeiros escritos, não será até anos depois que a autora começa a desenvolver sistematicamente o que essa terceira dimensão da justiça consiste, ou seja, representação política, a arena em que as outras duas dimensões da justiça são confrontadas. Em seu livro Escalas de Justicia (2008) Fraser refere-se a uma escala e um mapa. O equilíbrio simboliza o desafio colocado pelas visões conflitantes sobre o "o quê" da justiça: redistribuição, reconhecimento ou representação, enquanto no que diz respeito ao mapa o problema está nos quadros conflitantes referentes a "quem" conta como um verdadeiro sujeito de justiça. Não há dúvida de que ambos os aspectos desafiam e exigem uma resposta poderosa do ponto de vista de crianças e adolescentes como parte de uma sociedade que visa alcançar justiça para todos os seus membros.

Para Fraser, o significado geral da justiça é a paridade de participação. Isso exige acordos sociais que permitam a todos participar como pares na vida social e superar a injustiça significa desmontar os obstáculos institucionalizados que impedem alguns de participar em par com outros, como parceiros plenos na interação social. Alguns desses obstáculos não serão redutíveis à má distribuição ou à falta de reconhecimento, mas sim à constituição política da sociedade. Assim, uma representação fracassada (deturpação) ocorre quando as fronteiras políticas e/ou as regras de tomada de decisão políticas funcionam injustamente, negando a certas pessoas a possibilidade de se envolverem em paridade com outras (2008, p. 43). Dentro dele a autora distinguedois tipos. Por um lado, uma representação político-ordinária fracassada, que ocorre quando as regras de representação em uma determinada comunidade política, negam a paridade de participação a alguns dos que são nominalmente incluídos (caso de diferentes formas de representatividade nos sistemas eleitorais). O segundo tipo é quando a representação 
fracassada toma uma forma mais profunda, que Fraser chama de "desenquadrar" ou, "sem moldura" (misframing) e que ocorre quando as fronteiras se produzem de tal forma que alguns são excluídos da possibilidade de participar das alegações judiciais que são de sua responsabilidade. Ainda mais grave é o caso quando alguém é excluído de se associar a qualquer comunidade política, sem "direito a direitos" (em termos expressos por Hanna Arendt). Aqueles que sofrem esta exclusão:

Eles possivelmente se tornam objetos de caridade ou benevolência. Mas, privados da possibilidade de serem os autores de reivindicações de primeira ordem, não são pessoas no que diz respeito à justiça. (op. cit., p. 46)

Compreendidos no âmbito de uma cidadania concebida no sentido clássico (adesão a uma comunidade definida territorialmente e exercida por indivíduos que reconheceram o status de cidadãos), os argumentos anteriores deixariam de lado crianças e adolescentes, que seriam excluídos dessa forma de compreensão da comunidade política. Neste ponto é necessário recorrer a outros autores que concebem a cidadania das crianças dentro de visões mais amplas que são impostas diante da realidade de um mundo globalizado e interconectado, onde novos atores emergem com suas próprias reivindicações. Citar algumas dessas visões, juntamente com os cidadãos supracitados de baixo e cidadania focada na diferença seria a concepção da cidadania como prática (LAWY; BIESTA, 2006) que se constrói através de seu exercício na experiência cotidiana das relações interpessoais e nos próprios ambientes de vida e convivência. Assim, você pode ver que as crianças são cidadãos e agem como tal, em espaços como comunidades, grupos, escolas e famílias, onde exploram os componentes da cidadania, tais como: direitos, responsabilidades e deveres, igualdade e respeito, participação e pertencimento, além de elaborar medidas para alcançar suas reivindicações de justiça social nas esferas local e internacional (LARKINS, 2012).

Até a própria Nancy Fraser oferece uma janela aberta para a inclusão das crianças no contexto de paridade participativa ao se referir ao "princípio todo-sujeito", para o qual, "todos aqueles que estão sujeitos a uma determinada estrutura de governança estão em posição moral de estarem sujeitos à justiça em relação a essa estrutura" (op. cit, p. 126). Mas ainda haveria uma questão importante de como exatamente o princípio de "todos os sujeitos" deve ser implementado. Embora a resposta de Fraser seja orientada a pensar na invenção das instituições democráticas globais, dando preeminência às dimensões territoriais que limitam o exercício da cidadania, também é verdade que a autora termina o quarto capítulo de seu livro Escalas de 
Justicia falando do interesse pela emancipação e porque é reconstruída uma gramática da justiça que permite falar com o subalterno em termos credenciados (op. cit., p. 144).

\section{Conclusões}

Como tentamos demonstrar neste artigo, crianças e adolescentes poderiam ser considerados membros de um grupo que Fraser chama de "bivalentes", formas híbridas de comunidades que podem ser vítimas tanto da distribuição socioeconômica desfavorecida quanto do reconhecimento cultural inadequado, exigindo respostas da justiça, portanto, em ambas as dimensões. Mas sem nossa intenção de alterar a relação entre as duas dimensões propostas por Fraser, para que uma não possa ser totalmente explicada sem a outra, ousamos dizer que, no caso das crianças, o reconhecimento seria a dimensão mais necessária de atenção. Reconhecimento de sua real presença como atores na sociedade, contribuintes ativos para a mudança social, econômica e política. Por essa razão, seria também o reconhecimento essencial para expandir substancialmente seu espaço em termos de paridade participativa em todas as áreas da experiência cotidiana (incluindo especialmente a da família e da escola) e carregar sua voz, fazê-la ouvir e ver suas demandas na arena política respeitadas.

\section{REFERÊNCIAS}

ARCHARD, David; MACLEOD, Colin M. (eds.). O Estado Moral e Político das Crianças. Oxford: Oxford University Press, 2002.

ESPING-ANDERSEN, Gosta; GALLI, Duncan; HEMERIJH, Anton; MYLES, John. Por que precisamos de um novo estado de bem-estar social. Oxford/Nova Iorque: Oxford, 2002.

FERNANDEZ, Josefina. "Crianças: Cidadãos de hoje ou amanhã?" Revista Alternativa. Cadernos de Serviço Social. n. 16 de 2009. p. 111-126.

FRASER, Nancy. Redistribuição e reconhecimento: rumo a uma visão integrada de justiça do Gênero International Journal of Political Philosophy. 8, 1996. p. 18-40.

FRASER, Nancy. Justiça Interruptus. Reflexões críticas sobre a "Condição Pós-Socialista". Nova Iorque e Londres: Routledge. 1997.

FRASER, Nancy. Da redistribuição ao reconhecimento? Dilemas da justiça na era "póssocialista". New Left Review, nº 0, 2000. p. 126-155. 
FRASER, Nancy. Justiça social na era da política identitária: Redistribuição, reconhecimento e participação. In: FRASER, Nancy; HONNETH, Ariel. Redistribuição ou reconhecimento? Morata, 2006. p. 17-88.

FRASER, Nancy. Escalas da justiça. Barcelona: Pastor, 2008.

FRASER, Nancy. Política feminista na era do reconhecimento: uma abordagem bidimensional para a justiça de gênero. ARENAL, 19:2; Julho-Dezembro de 2012, p. 267-286

FRASER, Nancy. Da redistribuição ao reconhecimento? Dilemas da justiça na era "póssocialista". Em J. Butler e N. Fraser Redistribuição ou Reconhecimento? Um debate entre marxismo e feminismo. Madrid: Traficantes de Sonhos. 2016. p.23-66.

FRASER, Nancy; HONNETH, Ariel. Redistribuição ou reconhecimento? Madrid: Morata. 2006.

GAITÁN MUÑOZ, Loudes. "A nova sociologia da infância. Contribuições de um olhar diferente" Política e Sociedade, 43-1, 2006. p. 9-26.

GAITÁN MUÑOZ, Loudes. De "menores" a protagonistas. Os direitos das crianças no trabalho social. Madrid: CGTS, 2014a.

GAITÁN MUÑOZ, Loudes. Cidadãos na escola, ou a participação das crianças no processo educacional. Uma visão sociológica. Revista Escenarios, 15, 2014b. p. 75-102.

GAITÁN MUÑOZ, Loudes . Os direitos humanos das crianças: cidadania além dos "3Ps", Sociedade e Crianças, 2, 2018. p. 17-37.

GAITÁN MUÑOZ, Loudes; LIEBEL, Manfred. Cidadania e direitos de participação das crianças. Síntese, 2011.

GIDDENS, Anthony. Sociologia. Madrid: Aliança Editorial, 2000.

GOUVEIA, Maria Cristina Soares; CARVALHO, Levindo Diniz; FREITAS, Fabio Accardo de; BIZZOTTO, Luciana Maciel. O protagonismo infantil no interior de movimentos sociais contemporâneos no Brasil, Sociedad e Infancias, 3, 2019. p. 43-63.

HART, Roger. A participação das crianças: da participação simbólica à participação autêntica. Florence: Innocenti, 1992.

O IAWGCP. Crianças como cidadãos ativos. Um guia de política e programa -

Compromissos e obrigações para os direitos cívicos das crianças e o engajamento cívico no leste da Ásia e no Pacífico (en línea), 2008.

http://resourcecentre.savethechildren.se/library/children-active-citizens-policy-andprogramme-guide-commitments-and-obligations-childrens, accesoel 20 de febrero de 2019.

JAMES, Alison. "Agency" en Qvortrup, J., Corsaro, W. A. y Honig, M. (eds.) The Palgrave Handbook of Childhood Studie s. Londres: Palgrave Macmillan, 2011. p. 34-45. 
JAMES, Alison; PROUT, Alan (Eds.). Construindo e Reconstruindo a Infância. Falmer Press, 1997.

JENKS, Chris (ed.). A Sociologia da Infância. Leituras Essenciais. Gregg Revivals, 1992.

LARKINS, Gato. "Enquadrando a cidadania das crianças: explorando o espaço de reivindicações infantis de justiça social usando a concepção de representação de Nancy Fraser, 2012.

LAWY, Robert; BIESTA; Gert. "Cidadania como Prática: As Implicações Educacionais de uma Compreensão Inclusiva e Relacional da Cidadania" British Journal of Educational Studies, 54 (1), 2006, p. 34-50.

LIEBEL, Manfred. "Os movimentos das crianças trabalhadoras. Uma Abordagem da Sociologia" Política e Sociedade, 43, (1), 2006. p. 105-123.

http://www.ucm.es/BUCM/revistas/cps/11308001/articulos/POSO0606130105A.PDF, acesso 2 de dezembro de 2019.

LIEBEL, Manfred. "Cidadania de Baixo. Direitos das Crianças e Movimentos Sociais" en Invernizzi, A. y J. Williams (eds.). Crianças e Cidadania. Los Angeles, Londres, Nueva Delhi y Cingapura: SAGE Publications, 2008, p. 32-43.

MAYALL, Berry. Rumo a uma Sociologia para a Infância. Pensando na vida das crianças. Buckingham: Open University Press, 2002.

MAYALL, Berry. "Geração e gênero: estudos infantis e feminismo". En: MAYALL, B.;ZEIZER, H. (Eds.) Infância em Perspectiva Geracional.Londres: Instituto de Educação, 2003.

MOOSA-MITHA, M. "Uma Alternativa Centrada na Diferença para a Teorização dos Direitos de Cidadania das Crianças" Estudos de Cidadania, 9 (4), 2005. p. 369-388.

OAKLEY, Ann. "Mulheres e Crianças Primeiro em Última: Paralelos e Diferenças entre Estudos infantis e femininos". Relatório Eurosocial 47. Viena: Centro Europeo, 1993.

OLK, Thomas. Crianças, Relações Geracionais e Justiça Intergeracional. En J. Qvortrup et al. Infância Estudos. Basingstoke: Palgrave, 2011.

OLK, Thomas; WINTERSBERGER, Helmut. "Estados de Bem-Estar Social e Ordem Geracional". In:WINTERSBERGER;Helmut. et al. (eds).Infância, Ordem Geracional e o Estado de Bem-Estar Social: Explorando o Bem-Estar Social e Econômico das Crianças. Odense: University Press of Southern Yrnamarca, 2017.

PAVEZ SOTO, Iskra; KATTAN SERED, Natalia. Conceito de agência em estudos infantis. Uma revisão teórica, Sociedade e Crianças, 3, 2019. p. 193-210.

QVORTRUP, Jens. A infância como fenômeno social. Relatório Nacional Dinamarca. Viena: Centro Europeu, 1990. 
QVORTRUP, Jens. A infância como fenômeno social. Uma introdução a uma série de relatórios nacionais. Relatório Eurosocial 36/1990. Viena, Centro Europeo, 1990.

QVORTRUP, Jens. "Nove teses sobre a Infância como fenômeno social". Relatório Eurosocial 47/1993. Viena, Centro Europeo, 1993. p. 11-18.

ROSEN, Rachel; TWANLEY, Katherine. (eds.). Feminismo e a Política de Amigos de Infância ou Inimigos? UCL Press: Londres, 2018.

VERHELLEN, Eugeen. Direitos de Crianças e Participação. En: HEILIÖ, P. L.; LAURONEN, E., BARDY, M. (eds.). Política de Infância e Crianças em Risco. Provisão Proteção - Participação. Viena: Centro Europeu de Política e Pesquisa de Bem-Estar Social, 1993. p. 121-130.

VOLTARELLI, Monique Aparecida, GAITON MUOZ, Lourdes, LEYRA FATOU, Begoña: "A sociologia da infância e Bourdieu: diálogos no campo nos países de língua espanhola", Política e Sociedade, 55(1), 2018. p. 283-309.

WINTERSBERGER, Helmut. "Idade Eleitoral, dezesseis anos. A Reforma Eleitoral Austríaca de 2007". Revista de Estudos da Juventude. No 85 (edição online) Documento 2, 2009. p. 122. http://www.injuve.es/contenidos.downloadatt.action?id=2018997836

WYNESS, Michael. "Participação infantil: definições, narrativas e disputas" en Claudio Baraldi y Tom Cockburn (eds.) Theorising Childhood: Citizenship, Rights and Participation. Londres: Palgrave Macmillan, 2018. p. 53-72.

\section{SOBRE A AUTORA:}

\section{Lourdes Gaitán Muñoz}

Doutora em Sociologia pela Universidade Complutense de Madrid (Espanha), Associação "Grupo de Sociologia de Crianças e Adolescência", GSIA. E-mail lourdesgaitan22@ gmail.com (iD) http://orcid.org/0000-0002-4653-9533

\section{TRADUÇÃO LIVRE}

\section{Marcia Aparecida Gobbi}

Possui Doutorado em Educação pela Universidade Estadual de Campinas. Professora da Faculdade de Educação da Universidade de São Paulo, atuando nos cursos de Licenciatura em Ciências Sociais e de Pedagogia e junto ao Programa de Pós-Graduação em Educação. Atualmente dedica-se a investigar representações e criações da infância em luta por moradia em ocupações na cidade de São Paulo. Coordenadora do Grupo de Estudos e Pesquisas "Crianças, práticas urbanas, gênero e imagens" (CNPq/FE/USP). E-mail: mgobbi@usp.br iD http//orcid.org/0000-0001-9850-01901 


\section{$\underline{\text { REVISÃO TÉCNICA }}$}

\section{Sônia Larrubia}

Possui Mestrado em Educação, atuou 33 anos na Rede Municipal de Ensino de São Paulo como professora de Educação Infantil, Coordenadora Pedagógica, Supervisora Escolar e Diretora da Divisão de Educação Infantil da SME SP. E-mail: sonialv641@gmail.com

\section{Monique Voltarelli}

Doutora em Educação pela Universidade de São Paulo, Professora Adjunta da Faculdade de Educação da Universidade de Brasília e pesquisadora do Grupo de Estudos e Pesquisa Sociologia da Infância e Educação Infantil (GEPSI) da Faculdade de Educação da USP. E-mail: moniquevoltarelli@yahoo.com.br

(iD http://orcid.org/0000-0003-2605-0930

\section{TRADUÇÃO DE RESUMO EM INGLÊS}

\section{Maria Cristina Stello Leite}

Mestre e doutoranda em Educação pela Faculdade de Educação da USP, membro do grupo de estudos e pesquisas "Crianças, práticas urbanas, gênero e imagens" (CNPq/FE/USP). E-mail: mariastello@gmail.com

iD http//orcid.org/0000-0001-7418-1463

Recebido em: 25 de janeiro de 2020 